\title{
A Study on the Relationships between Home-Oriented And Culture Creative Industry in Taiwan
}

\author{
Hsieh Ming-cheng ${ }^{1}$, Hsieh Ming-jui ${ }^{2}$ \\ ${ }^{1} \mathrm{PhD}$ Student of Graduate Institute of Cultural \& Creative Design, \\ Tung Fang Design Institute, Kaohsiung, Taiwan \\ ${ }^{2}$ Chairman of Sino International Business Innovation Association, Taipei, Taiwan \\ . E-mail : hmingjui@gmail.com, \\ E-mail : ming@rmail.nou.edu.tw
}

\begin{abstract}
The government counseling to the SMEs were forced on the manufacturing or export industry in Taiwan, but the counseling policy translate to the home-oriented industry with the high and high contribution to the economic growth were come from the Service Industry improve gradually; the SMEs of Ministry of Economic began to made a counseling policy to the features of home-oriented industry since 1989, it was promoted to home-oriented industry under the target of One Town One Product (OTOP)in 2002; and the policy translate to the operation mode of Industry Development Fund in2009; the government promoted creative industry actively from the OTOP plans, home-oriented industry, to the culture creative industry in 2012, it bring to the good results on the people's employment and life quality, the famous and success case such as A-Yuan Works, Yard of Sky, Monster Village...etc., were transfer from the Home-oriented Industry to the Culture Creative Industry gradually, it injected the vitality to the local construction and national economic development simultaneously. the methodology in this study is the literature analysis and try to know the relationships between the home-oriented and culture creative industry in Taiwan.
\end{abstract}

Key words : OTOP Home-oriented Industry Culture Creative Industries

\section{Introduction}

Only on the open and free society can produce the broad ideas under the free economy. It has not only those products such as the Franz, Glass studios are well-known international brand of creative industries in Taiwan, the local place also has a small creative shops to attract those international investors come to visit and buy those products of home industries.

The Bypass Plans of International and Both Sides of Culture Create Industry Organizations was planned by the Ministry of Culture in 2012, and according to the Taiwan Creative Design Center, the main theme adopt to the across domain cooperation, it combined music, animation, design, technology, and the different skills , it also combine the agricultural, manufacturing and services industry, so the added value of culture creative industry can show the heritage culture, It create a good opportunities for the entrepreneurs' development, and has a great help to the local employment and economic development in Taiwan.

The methodology in this paper was based on the literature analysis, the content and implementation of the domestic OTOP program, as well as the promotion of the cultural connotation of the creative industries 
that was hold by concerned developments of government, its features and the manner of execution indicate to the correction between the home-oriented and creative industries in Taiwan.

\section{Literature review}

The concerned literatures as following:

Liu Xinyuan (2009)

This paper has a concept clear to the creative industry, and made a proposed recommends to the creative policy, it include to those recommendations such as no imitation to the culture creative method of United Kingdom, no investment replaced grants of policy which caused serious hurt to the culture development and art environment in Taiwan. Besides that, it should be set up the integration of related departments and resources, to facilitate the development of creative industries in order to promote creative entrepreneurship in Taiwan.

Hsieh, Ming-jui; Lin Zhenhuang (2010)

According to Hsieh's research, the "Bang Bag Puppet Play" was a highlights of industry features among many culture creative industries in which show the multiple and rich of culture connotation, it is one of the bigger scale of culture industry, and the Bang Culture Creative Industry was produced in order to match economic development in Taiwan. Besides that, the development of Bang Bag Play from traditional market, videos market, and to the audio market (including wireless TV, wired TV, and movie) etc. under the operation and management process of culture industry, it went out from the traditional television market, and modified into the family convenience store of rental film market in Taiwan.

CEPD (2011)

The main ideas of the "Home has Industry and Industry has Home Plan" is the combination of the concept of suitable distract and industry, the operation of home industry enhance the competitiveness of industries in order to increase employment opportunities, improve income, share benefits of industrial development in each regions. So, the main purpose to the "Industry has Home and Home has Industry" plan is to promote the employment in each distract, for the plans can assist established partners relationship between the central and local government, if each city can found its industry to developing, it should can improve economic growth rate effectively, reduced unemployment, and shortened the gap between to the urban and rural, and avoid to the unfair distribution.

Hsieh Ming-jui (2013),

According to the Hsieh's research, the forward base urban regeneration plan mainly through urban renewal or regeneration that will creative more dynamic activities and public benefits. This article forced on the "rebirth" of the URS plan, according to each region's characteristics and planning, different types of creative clusters, creating traditional, humanistic, creative, and other creative blocks through clustering to build a creative city. Besides that, the cultural create cluster promoted to different type of cultural create cluster district through the cooperation mode, and try to built a creative city under the concept of "regeneration" to the value of city in which through cluster effect and industry development in Taiwan. 


\section{The Home-Oriented Industry}

The Home-oriented industry based on the planning of OTOP (One Town One Product) that was promoted by the Ministry of Economics Affairs, the Executive Yuan held the plan of "Taiwan Home Industries with Create Added Value Guidance Planning" on the all country in order to training of local talents, and its direction for the development of the local industry, and combined with policies such as the "features of one town one product", "community feature creating", "rural regeneration" etc, coupled with network marketing and cultural creative, and increasing to the opportunities of business and employment.

\subsection{Background of Home Industry}

The SME of the Ministry of Economic Affairs held the OTOP plans in order to promote local economic and has help to the domestic economic growth in 1989, the plan was adopted the analysis model that combined to the policy of the Central Government, opinion of scholars experts in the local government, and the developed idea of counseling teams, provides to the base counseling on the potential and regional features of local product, and towards the main aim of one town and one product.

\subsection{Definition of Home Industry}

In general, the home industry is a local industry with local characteristics, the so called local category is mainly based on village, town, city, and the special industry had concerned to the features of historic, culture and unique of local industry.

\subsection{Characteristics of Home Industry}

The local industry with local characteristics has its production advantage within a certain district in which those features can be summarized as follows:

- The function of preservation and development of cultural or traditional craft skills.

- It was focused on the local or community relations.

- It has a closely relationships with the local economic and social affair.

\subsection{Classification of local features industry}

In generally, the classification of local industry can roughly divide into several classes as following:

- Pastoral Leisure: For the various special terrain and rich changeable of surface morphology in Taiwan, it also brings special natural landscape and commercial activities, those districts such as the boating, back Brook, Spa, cold spring, and forest amusement and so on.

- Agricultural products: The agriculture industry is the dominated industry in early Taiwan, the use of local agricultural and livestock products processing such as the Lotus industry in Pai Ho, Coconut industries in Pingtung, Gong Candy industry in King Men and so on, are the epitome of agricultural products category.

- Art products: Art products are as the using conditions such as the local raw materials, climate and the territory, it was merged into the conservation unique of history culture, the civilization and skills 
evolution course during the manufacturing process; so the combine product of culture and art is the labor intensive wok, it cannot produced in a large manufacturing process, but has a good value of storage, its extension products can be divided into technology, agro-products and leisure products.

- Religious culture products: According to the folk and religious belief in each area, it contributed to the culture art activities to the community create and reconstruction by the original or new development of culture and art activities, the culture will became to the assets of industry and has helpful to the local development, it can be revitalize to the concerned local economic activities, such as the Tachia Matsu pilgrimage activities, and it was a good base on the religious culture team to expanded the revitalization of local culture and economic development.

\subsection{Development of Local Features Industry}

The features of the local industry include to those fields such as food, clothing, living,transportation, education and entertainment, the working contents such as the labor's training, local organization, development of community and industry, the operating and counseling on the small and medium enterprise, financial facility, marketing promotion, packaging design, and products development, it need to proposed integration counseling mechanism, and promoted by professional counseling teams of the local government.

\section{Cultural and Creative Industry}

The Cultural and Creative Industry was the industry that based on the "Cultural and Creative Industry Development Plan" under the "Challenge 2008: National Development Plan" that was established by the government in 2002, However, there have different definitions of cultural and creative industries in each country. Those countries were including the United Kingdom, Korea, the United States, Japan, Finland, France, Germany, Italy, Australia, New Zealand, Denmark, and Sweden ...etc.

\subsection{Originality}

The United Kingdom forced on the policy of the culture and creative industry development in 1977, the policy can considered as the first of creative industry policy that was promoted by the Government; South Korea also began develop her "culture industry" from movie and digital industry simultaneously; the Australia, New Zealand, and all most of countries in the European were joined gradually also; China joining to the creative term after 2000, her art market flourish, and the big construction of public performances site such as the 798 special district, it try to search of the better way to develop under the advantage of manufacturing industry. It forced on the development of creative industries also, and some of them were copy from Taiwan's model.

\subsection{Definition of Culture Creative Industry}

The definition of culture creative industry has different meaning in each country, if according to the definition by David Hesmondhalgh, the products of culture industry can interpret by any people whose include to the songs, narrations, and performances etc., it mainly caused mind reaction and characterization of culture 
in order to reached the target of communication, and the around culture industries such as theatre, Visual art, software, consumption on the electronic products, popular fashion, crafts, and construction and so on.

\subsection{Characteristics of The Cultural Industries}

In general, the concept of cultural industries includes to the "popular culture" or "pop art", such as commercial design, TV shows... etc., its main characteristics are as following:

- Behavior of Culture industry

It is the combination of industry and culture.

- Operation of Enterprise mode

It is the combine model of cultural and commercial business.

- Market transformation of cultural value

The cultural value can accomplish by the conversion process from market mechanisms.

- Cultural and economic functions

The creative industries is realizing the economic attributes, economic value of culture and the ideology of cultural and spiritual values.

- Combination of high tech and high intelligence

The culture industry is a knowledge economy with high performance.

\subsection{Principle of Selection in Cultural Industries}

The selected principles of cultural industries by the government are as follows:

- Principle of Majority: A number of employment or participation with a majority was selected by government.

- Principle of Associate Benefit: The associated benefit was selected by government, the big connections and the high potential growth.

- Principle of Added Value: In accordance with the characteristics of the originality, innovations, added value for the selection, the higher the better.

\section{Connection of the Home Industry and the Creative Industries}

The connection between the home and the creative industry can be illustrate as following:

\subsection{Combination of the Different Industry}

In generally, the home industry has local features in which include to the package of food, clothing, living, transportation, education, and entertainment, it has a great correction between the local activities and economic development, and the creative industry promote economic development through to the creative industry, it include to the movie, TV, music, design, game and so on, and the combination of home industries and creative industries which can create more opportunities for business and more benefits for consumers.

\subsection{Combination of Culture and Commercial Activities}

On the promotion of practice in business, the creative industry has advocates the cooperation between 
cultural and commercial activities, it has advocates the idea of "creative value-added", and the field of creative culture main including those items such as design, media, advertising, building, new products, and new brand of products, so the creative industry can take a starting point from consumption to high level of cultural consumption by using the combine factors of cultural and commercial activities.

\subsection{Combination of Home Industry and Creative Industry}

Owing to the OTOP plans has its unique of the local history culture, and regardless of the agricultural products or art products, also pastoral leisure or religious culture, are has the innovational factors of local culture and industry, its similar to the content of culture creative industry that was promoted by the Government. So, the OTOP plan was promoted by the local government, it can improve the people's standard of living and to promote the social progress and increase to the economic growth.

In addition, it has the similar connotation between the home industries and creative industries, it was based on the industry combination by caused of accelerated phenomenon or multiplier effect, it will helps to the industry development or national economic growth, so, the Government also need to encourages the linkage between the home industry and creative industry, such as the Culture Create Added Value Counseling Plan was held by the Ministry of Culture annually, the features industry has concern to the historic and culture creative industry on the network marketing to the home industry, Each town has her special product and mainly industry in order to increase in employment opportunities, encourage domestic and foreign investments, and achieve to the aim of local economy activities vibratory.

\subsection{Impact of the Combination Between Home and Creative Industries}

The impact of the combination between the home industry and culture creative industry can be divided into the following sections:

- Mainstream economy: The CEPD's plan of the "Industries has its Home and Home has its Industries" was based on the local and industrial properties to the regional economic framework, it combine to the package groups with the core and arounding cities, marketing together, build brand, and global investment, it can introduce more resources and being to the mainstream of economic development in Taiwan.

- Combination of multi-officials: Government should be understand the advantage situation of the local industry, and owing to the home industry and culture create industry has the characteristics of local culture and commercial business, it shall be adopt an appropriate way to made a cooperation, so it can be combined to the ability power of experts and scholars, and the links between the home industry and creative industry under the joint assisting on the central and local government, it can be created more value of production, and to achieve the aims of economic development.

- Culture Create Added Value of Home Industry: The Executive Yuan had established a team to promoted the culture creative industry in 2009; However, owing to the culture creative products are not equal to the culture creative industry; The culture creative has unique feature, but it need has the suitable technology and methodology if the creative product translate to the creative industry, its mean the industry 
development has concept that the output increasing from expanded products, business operation and the direction of industry.

- Development of Industrial Promotion: The combination of home industries and culture creative industries can make the local industrial development expanded into the regional economic, such as the combination of seven cities to develop tourism activities in order to reach a certain market size in the North Taiwan. Because there are about $80 \%$ of creative resources were centralize in the North Taiwan, the brand of North District will have a marketing capabilities and the surrounding marketing, it will impact on the development of the market economy after the clustering effect were produce among the core and neighboring cities.

- Equilibrium in regional economic: Except to the geographical and regional feature can caused cluster effect, the similar industry also can formed regional economic such as the component industry developed in Hsinchu, if it can match to the using of precision mechanical industry in Taichung, that is an industry group in Taiwan, and the component needs more in India and Southeast Asia countries, so as long as the Enterprise operators concentrated on the products in this two cities, it will can reached the made profit of purpose. In addition, the Government can use tax and fiscal policies to achieve the goal of industry development equilibrium in Taiwan.

\section{Conclusions and Recommendations}

According to the foregoing analysis and description, it may list the conclusions and recommendations are as followings.

\subsection{Conclusions}

The conclusion in this research are as following:

- The culture creative industry can play the role of culture heritage and creative idea exploration into the real life in Taiwan, it has a great help to the local employment and national economic development.

- The cultural creative industry based on the accumulation of creative idea and cultural fulfillment through the using of intellectual property, it can promote the overall living environment well.

- The products of cultural industries can cause the human mind response, and its surrounding cultural industries are the contents of the creative industries, its main characteristics are the combination of high tech and high intelligence.

- The connection of the home industry and the creative industries include to the combination among the different nature of the industry, and its effects can promote industrial development as well as the balance of regional economic.

\subsection{Recommendations}

According to the foregoing conclusions, the recommendations of this study can be listed as follows:

- The cultural creative industry has the potential for creating wealth and employment opportunities, so the Government must be planned and promoted efficiently to the creative industry in Taiwan. 
- $\quad$ The home industry has its local characteristics, its select principles including the factors such as the majority, benefits and value, however, the create added value of the culture creative industry need to expanded output, and has integrate marketing with practices.

- The Government need to promote the combination of home industries and creative industries with the high-tech and intellectual people.

- It is necessary to promote actively on those items such as aesthetic education, culture creative foundations and concerned laws and so on, in order to support the development of creative industries as well as a good creative environment.

\section{References}

[1] David Throsby, "Cultural Economics," Art Collector's Company, Taipei.2001.

[2] Lin Zhenhuang, "A Study on the operation and management of the cultural and creative industries-a case study of puppet play," Cultural Creative Academic Excellence Symposium, National Taipei University of Education. 2010..

[3] Hsieh Ming-jui, "The Changes from the OTOP scheme and Home Industry to the Culture Creative Industry," National Policy Research Foundation. 2012.

[4] Hsieh Ming-jui, "The Creative Industries and Urban Renewal-URS," National Policy Research Foundation.2013.

[5] Liu Hsin-yuan, " What are the Cultural and Creative Industries?" National Policy Research Foundation.2009.

[6] CEPD,"The Plan on the Industry has its Home and Home has its Industry," the Executive Yuan.2006. 